\title{
Coexisting B- Cell Lymphoma and Benign Mesenchymal Phospaturic Tumor: Debut as Acute Renal Failure Associated with Hypercalcemia and Hypophosphatemia
}

\author{
Navas-Parejo Casado AM, Peña Ortega $\mathbf{M}^{*}$, Caba Molina M, Burbano Terán CM and Bravo Soto J
}

Department of Nephrology, Servicio De Nefrología, Hospital Universitario San Cecilio, Granada, Spain

\begin{abstract}
The present case starts as an acute renal failure related to severe hypercalcemia, hypophosphatemia, increased FGF-23 and decreased TRP. All the previous are associated with increased bone exchange rate, low $\mathrm{PTH}$, undetectable levels of PTH-RP, 1-25 OH Vitamin D3 in upper level of normal range and bone densitometry compatible with osteoporosis in trabecular bone. These results seem compatible with an increase in bone resorption, urinary loss of calcium and phosphate, and none induced by PTH. Complementary studies suggest the spleen is the organ directly related with this case. In conclusion, a B Cell Lymphoma was diagnosed. It explained the causes of the hypercalcemia, either by the effect of a lymphotoxin, TNF or interleukin 1. After total remission of the lymphoma, the hypophosphatemia persisted, as did the Hight levels of FGF-23, low levels of TPR and a pathological bone densitometry. This lead us to believe in the presence of a phosphatizing producer tumor located in the spleen. Once the splenectomy was done, the analytical findings returned to normal and the histologic evidence confirmed the initial clinical prediction.
\end{abstract}

Keywords: Tumor; Hepatosplenomegaly; Hypercalcemia

\section{Introduction}

Hypercalcemia can be caused by one or a combination of the following factors: endocrine, metabolic, hereditary and/or acquired causes. Tumors cause hypercalcemia either by bone metastatic disease or by producing PTH-like substances. Hypophosphatemia, on the other hand, may result from malnutrition, renal tubular disorders or oncogenic osteocalcin. The latter, which is quite rare, may be associated with phosphatizing producing tumors 1 and 2 . In the present case study both conditions, tumoral hypercalcemia and hypophosphatemia occur simultaneously, and are induced by a phosphatidic tumor.

\section{Case Report}

A 39-year-old male patient, who was referred to our hospital due to acute kidney conditions with elevated serum creatinine levels 4.2 $\mathrm{mg} / \mathrm{dl}\left(\mathrm{GFR}\right.$ by MDRD $17 \mathrm{ml} / \mathrm{m} / 1.73 \mathrm{~m}^{2}$ ) and severe hypercalcemia (Ca $15.4 \mathrm{mg} / \mathrm{dl})$. The patient's past medical history reports restless legs syndrome, akathisia, disc hernia (L5-S1) and osteopenia. He has been administered pramipexole and alendronate and has no known drug allergies. Review of systems otherwise unremarkable. The patient's metrics are as follows weight $72 \mathrm{~kg}$, height $1.82 \mathrm{~m}$. he is well developed, well nourished, has no acute distress, skin rashes or lesions. His pupils are equal in size, neurologically intact, reactive to light, and present adequate accommodation to stimulate. In terms of general heath, his eyes, ears and throat seem normal. Upon examination, his neck feels normal, so does the patient's heart and chest. Soft, no tender abdomen, no hepatosplenomegaly or masses to touch. His extremities to tact show full pulses and no edema.

At admission on $12 / 08$, his test results and blood work are as follows: Glucose $90 \mathrm{mg} / \mathrm{dL}$, Urea $60 \mathrm{mg} / \mathrm{dL}$, Creatinine $2.5 \mathrm{mg} /$ $\mathrm{dL}$ (MDRD $31 \mathrm{ml} / \mathrm{min} / 1.73 \mathrm{~m}^{2}$ ), Sodium $142 \mathrm{mEq} / \mathrm{L}$, Potassium $2.6 \mathrm{mEq} / \mathrm{L}$, Calcium $11.6 \mathrm{mg} / \mathrm{dL}$ (Corrected calcium $12.47 \mathrm{mg} / \mathrm{dl}$ ), Phosphate $1.7 \mathrm{mg} / \mathrm{dL}$, Magnesium $2.1 \mathrm{mg} / \mathrm{dL}$. His AST and ALT are within normal range. The results for total serum proteins are $6.2 \mathrm{~g} /$ $\mathrm{dL}$, while the Alkaline Phosphatase is $15 \mathrm{UI} / \mathrm{L}$ (range 40-130 UI/L) and the bone alkaline phosphatase $5.18 \mathrm{ug} / \mathrm{L}$ (range 3.5 to 20.3). The parathyroid gland is intact and the hormones (PTHi): $10 \mathrm{pg} /$ $\mathrm{ml}, \mathrm{PTH}-$ Related peptide (PTH-RP) $<0.3 \mathrm{pmol} / \mathrm{L}$, TSH: $2.13 \mathrm{uUI} /$ $\mathrm{mL}$ and 1-25(OH $)_{2}$. The levels for Vit.D3: $48 \mathrm{pg} / \mathrm{mL}$. Vit-B6: <4 $\mathrm{mcg} / \mathrm{L}$ (range 4-18), Pyridoxal-5- phosphate: normal, ECA: 56U/L are within normal ranges.

Likewise, the levels for osteocalcin $34 \mathrm{ng} / \mathrm{L}$, Beta-crosslap $1.234 \mathrm{ng} / \mathrm{mL}$, Pro-peptide collagen type $143 \mathrm{ng} / \mathrm{mL}$ (range 22 to 105). His serology for Hepatitis B virus, Hepatitis C Virus, Human immunodeficiency virus, toxoplasma and syphilis came out negative. In like manner, test results for autoimmunity: Antinuclear antibodies (ANA), antineutrophil cytoplasmic antibodies (ANCA), and antiDNA are negative as well. The complementary proteins $\mathrm{C} 3$ and $\mathrm{C} 4$ were found to be within normal ranges. The tumor markers: CA-125, CA.19.9, Ca 15.5, alpha-fetoprotein, PSA, Carcinoembryonic (CEA) are within normal ranges or negative. His urine sample contained normal sediment and had a $\mathrm{pH}$ of 7.5. While the patient's urine chemistry screening came out with Sodium $114 \mathrm{mEq} / \mathrm{L}$, Potassium $28 \mathrm{mEq} / \mathrm{L}$, Fractional Excretion of Sodium (FeNa) 4.5\%, Creatinine $48.5 \mathrm{mg} / \mathrm{dL}$ Calciuria $19 \mathrm{mg} / \mathrm{kg} /$ day. Ratio $\mathrm{Ca} / \mathrm{Cr}: 0.19$. Glycosuria $16 \mathrm{mg} / \mathrm{dL}$, tubular reabsorption of phosphate (TRP) $42.5 \%$.

Additional testing such as imaging studies exhibit a chest $\mathrm{x}$ ray without significant findings. Yet, no specific images on left hypocondrium for calcium density in the abdomen were taken. In

*Corresponding author: Peña OM, Department of Nephrology, Servicio De Nefrología, Hospital Universitario San Cecilio, Granada, Spain, Tel: +34 958023000; E-mail: maria3jl@yahoo.com

Received November 28, 2018; Accepted June 29, 2018; Published June 30, 2018

Citation: Navas-Parejo CAM, Peña OM, Caba MM, Burbano TCM, Bravo SJ (2018) Coexisting B- Cell Lymphoma and Benign Mesenchymal Phospaturic Tumor: Debut as Acute Renal Failure Associated with Hypercalcemia and Hypophosphatemia. J Clin Case Rep 8: 1137. doi: 10.4172/2165-7920.10001137

Copyright: (C2018 Navas-Parejo CAM, et al. This is an open-access article distributed under the terms of the Creative Commons Attribution License, which permits unrestricted use, distribution, and reproduction in any medium, provided the original author and source are credited. 
Citation: Navas-Parejo CAM, Peña OM, Caba MM, Burbano TCM, Bravo SJ (2018) Coexisting B- Cell Lymphoma and Benign Mesenchymal Phospaturic Tumor: Debut as Acute Renal Failure Associated with Hypercalcemia and Hypophosphatemia. J Clin Case Rep 8: 1137. doi: 10.4172/2165-7920.10001137

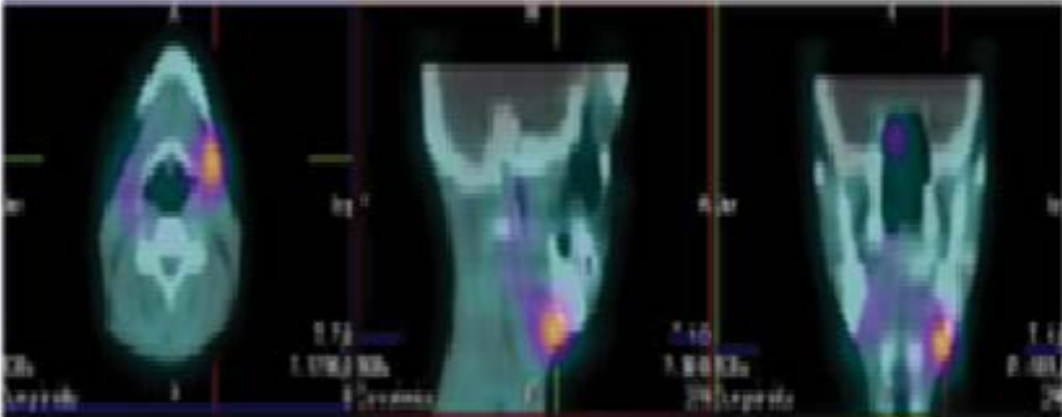

1A

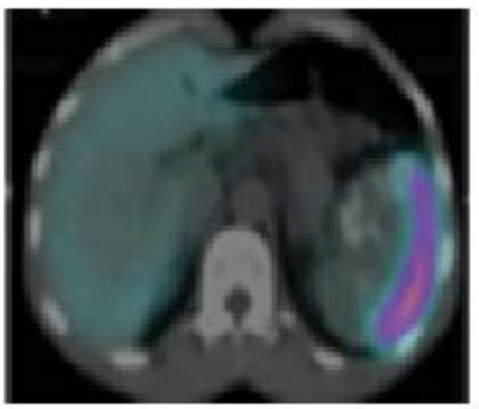

1B

Figure 1: Rastreo gammagráfico con OCTREOSCAN - PET TAC (03/2009): (A) Captación anómala de octeotride a nivel de región de glándula submandibular izquierda. (B) Importante aumento de tamaño del bazo, con una intensa captación en borde externo del mismo (fisiológica).

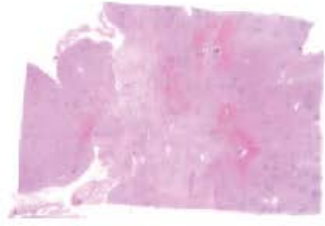

$2 A$

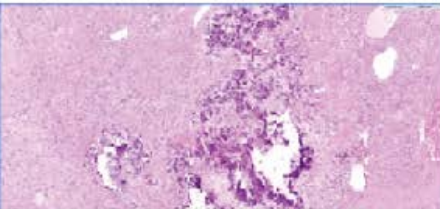

2D

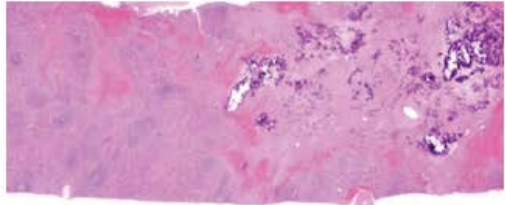

$2 B$

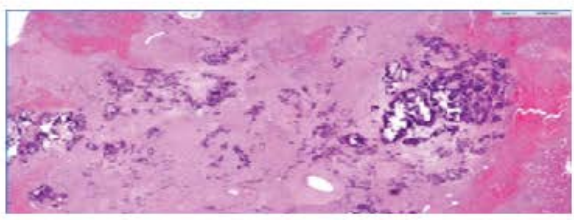

$2 \mathrm{C}$

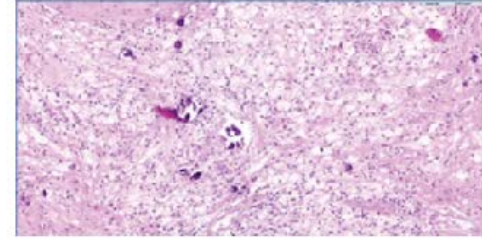

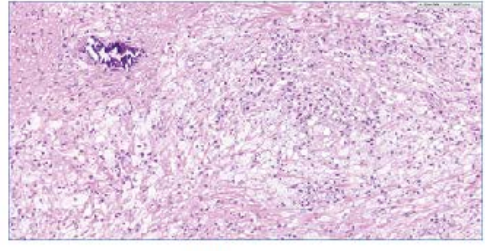

3B

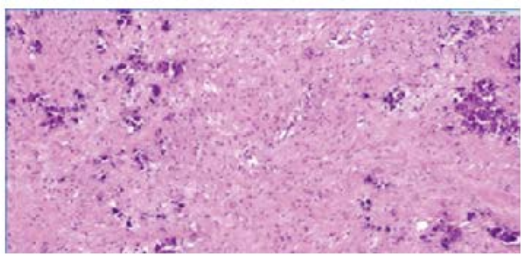

Figure 3(A-C): The annual bone densitometry showed a mild improvement in lumbar Z-score. 
Citation: Navas-Parejo CAM, Peña OM, Caba MM, Burbano TCM, Bravo SJ (2018) Coexisting B- Cell Lymphoma and Benign Mesenchymal Phospaturic Tumor: Debut as Acute Renal Failure Associated with Hypercalcemia and Hypophosphatemia. J Clin Case Rep 8: 1137. doi: $10.4172 / 2165-7920.10001137$

Page 3 of 5

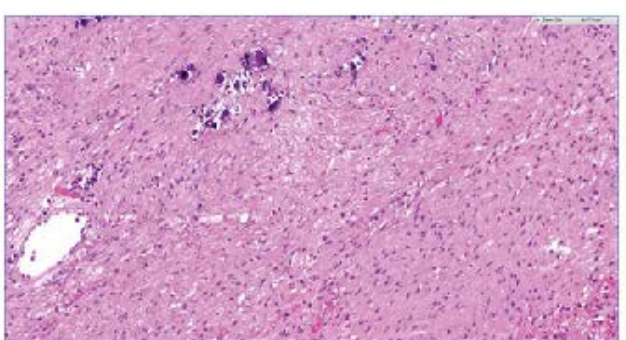

$4 \mathrm{~A}$

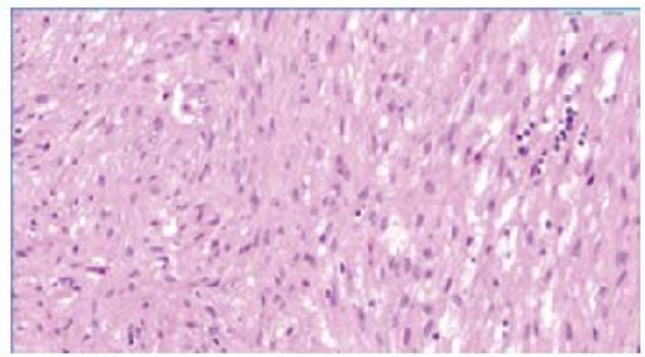

4C

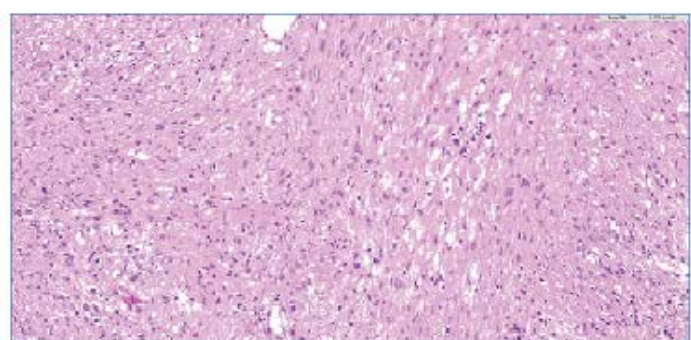

4B

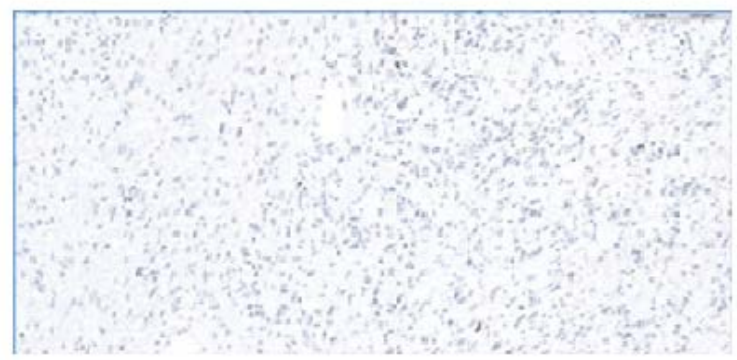

4D

Figure 4(A-D): Serum tumor markers were within normal range and that there was no evidence of monoclonal gammopathy.

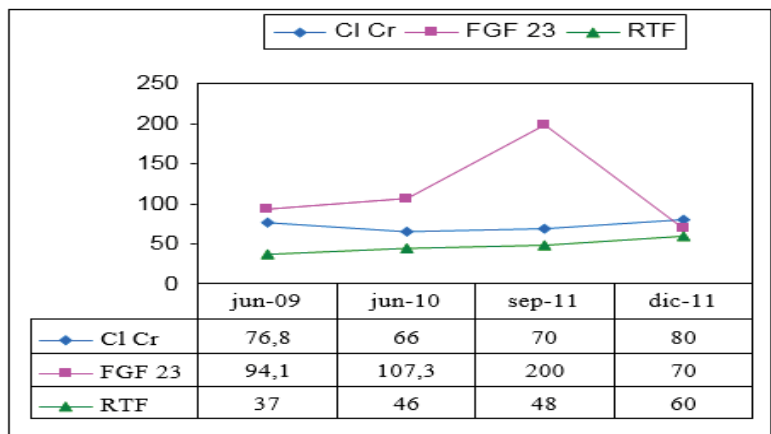

$\mathrm{C} 1 \mathrm{Cr}: \mathrm{ml} / \mathrm{min}, \mathrm{FGF} 23 \mathrm{KUA} / \mathrm{L}, \mathrm{RTF} \%$

Graph 1: Progression of analytical parameters during follow up.

the abdominal ultrasound one can observe normal size kidneys and loss of corticomedullary differentiation. The liver looks normal. However, the spleen is enlarged (splenomegaly) and contains many radial calcifications with a multilocular pattern, as shown by the thoracoabdominal computed tomography. There were no additional abnormalities identified. His bone scan depicts an increased uptake in his elbows, wrists and knees. On the other hand, the bone densitometry results for (DXA) are: Lumbar Z score: - 2.6, T score -2.7. Ward triangle: Z- score: -1.1 , T-score -0.5 .

Overall, the patient presented a favorable clinical evolution. His hypercalcemia was treated by stimulating diuresis with saline solution, coupled with the administration of prednisone and alendronate. The calcemia was reduced gradually and the renal function improved (Creatinine $1.6 \mathrm{mg} / \mathrm{dL}$, GFR by MDRD $82 \mathrm{ml} /$ $\mathrm{min} / 1.73 \mathrm{~m}^{2}$, Calcium $9.6 \mathrm{mg} / \mathrm{dL}$, Phosphate $1.6 \mathrm{mg} / \mathrm{dL}$, TRP $49.3 \%$,
Calciuria $3.98 \mathrm{mg} / \mathrm{kg} /$ day). The treatment at discharge included Pyridoxine, Vit D3 and joulie solution.

At this point, the initial cause for hypercalcemia remains unclear, even after hyperparathyroidism, hyperthyroidism, vitamin D intoxication, sarcoidosis, myeloma, PTH RP producing tumor and adult ç were discarded.

\section{Discussion}

Finding an elevated blood serum of FGF-23, three months after being discharged from the hospital, leads us to ponder the possibility of a Phosphatonin producing tumor present in the spleen. A SPECT-CT with Octeotride was performed (April 2009), which showed an enhancement in the left side of the lower jaw (Figures $1 \mathrm{~A}$ and $1 \mathrm{~B}$ ). An excisional biopsy was performed shortly afterwards. The histopathologic study results revealed a completely deformed lymph node, a lymphoid neoplasm with intermediate and enlarged cells, which had uneven contours and small nucleoli. The biopsy also came out with extensive necrotized areas and apoptosis $[1,2]$, as well as accelerated mitosis as can be seen in the starry sky image. The immunohistochemical results are positive for IgM (surface), CD20, CD79a, CD10, bc 16 and negative for bcl-2, Ki67 (+). The proliferative cells index is over $80 \%$. And, the molecular study was negative to translocation bcl2, bcl 6 and c.mycs. In conclusion, a diffuse large b-cell lymphoma was found (WHO 2008).

New cervical- thoracoabdominal CT reveled adenopathy conglomerate in left renal hilum, left adrenal gland and splenic hilum compatible with non- Hodking lymphoma stage IV. Spleen also presented heterogeneous formation $10 \mathrm{~cm}$ diameter of possible vascular origin with amorphous calcifications. Patient refused to bone marrow aspiration and biopsy (Figures 2A-2E).

Treatment started with R- CHOP chemotherapy regimen given in 21-day intervals $(6$ cycles $)$ resulting in complete remission 
Citation: Navas-Parejo CAM, Peña OM, Caba MM, Burbano TCM, Bravo SJ (2018) Coexisting B- Cell Lymphoma and Benign Mesenchymal Phospaturic Tumor: Debut as Acute Renal Failure Associated with Hypercalcemia and Hypophosphatemia. J Clin Case Rep 8: 1137. doi: 10.4172/2165-7920.10001137

Page 4 of 5

of lymphoma, with no relapse until present time. The patient continued with treatment for hypophosphatemia and maintained average levels for calcium of $10.5 \mathrm{mg} / \mathrm{dL}$ and for phosphorus of $2.5 \mathrm{mg} / \mathrm{dL}$. TRP 52\%. His glucoseuria fluctuates even with normal blood glucose levels, while his urinary $\mathrm{pH}$ is at 7.5 .

New FGF-23 quantification was done in October 2009 and blood levels of $107 \mathrm{KUA} / \mathrm{L}$ (17.6 to 28.8) were found. A new SPECT-CT with Octeotride and no contrast enhancement was also performed. This time, with no considerable findings other than a splenic mass. Follow up SPECT-CT were negative to new masses, while the annual bone densitometry showed a mild improvement in lumbar Z-score (-2.45) (Figures 3A-3C).

After a 28 month follow up, while then patient was still under treatment, hypophosphatemia was detected. Additionally, both, his TRP and bone mineral density with a $\mathrm{Z}$ score of -2.7 had decreased. Given these data and the patient's evolution, a splenectomy was performed in November 2011.

His FGF-23 levels were measured before and after the intervention. As seen on Graph 1, the values for FGF decreased significantly, the TRP showed improvement as did the glomerular filtration rate.

The microscopy performed to determine an anatomopathology of the spleen told us it had a weight of $191 \mathrm{~g}$ with normal dimensions $(17 \times 7 \times 3 \mathrm{~cm})$. It also depicted an irregular white yellowish lesion of $4 \times 3 \times 2.2 \mathrm{~cm}$ in the hilum with calcium consistency and good red/white pulp differentiation. At a microscopic level we saw a spleen with preserved architecture [3]. The hilum had a scanty proliferation of benign mesenchymal spindle-shaped cells infiltrating the spleen. The nuclei in the cells looked regular, with some foamy histiocytes and cholesterol crystals, as well as occasional multinucleate giant cells. Furthermore, the vessels walls were hyalinized. His inmunohistochemical study resulted negative to desmin, CD99, S-100, smooth muscle actin, CD34, BC12, EMA, cytokeratin and CD68. The mitotic activity was unapparent and had a very low proliferative index determined by staining for Ki-67. The diagnosis was: phosphaturic benign mesenchymal tumor.

\section{Comments}

The first case of tumor hyphophosphatemic osteomalacia was described in 1947 by Mc Cance [4] and recognized as such in 1959. A range of phosphatonin producing tumors of mesenchymal origin can cause this syndrome [5]. However, they are a rather rare cause of paraneoplastic syndrome. At first, in the case presented above, common causes of neoplastic hypercalcemia associated with neoplastic diseases were searched for. We found serum tumor markers were within normal range and that there was no evidence of monoclonal gammopathy (Figures 4A-4D).

Ruled out endocrine-metabolic findings were: hyperparathyroidism, hyperthyroidism and sarcoidosis. Adult hypophosphatasia FA baja is a rare disease, which presents low levels of alkaline phosphatase and pyridoxal-5-phosphate. It produces alterations related to calcium/phosphorus metabolism and chondrocalcinosis [5].

We are presented with an unusual case in this patient. That is, the presence of two tumors in the same subject. One is a benign mesenchymal tumor located in the spleen and produces FGF-23, which causes his hypophosphatemia. The other is a $\mathrm{B}$ cell lymphoma, that is responsible for hypercalcemia. The latter is likely to produce a hypercalcemic factor associated with hypercalciuria, a suppressed PTH-RP, an increase in Vitamin D, and elevated bone turnover markers. Which in turn portray a profile like corticosteroids responsive sarcoidosis [6].

Given the data during the initial hypercalcemia presented by the patient, (low PTH, low PTH- RP, low FA, imaging negative to other solid tumors, bone scan negative for metastasis) a phosphatonin producing tumor was considered and once the hypercalcemia was corrected, a treatment was put in place with Joulie solution and Vitamin D.

Six months later, the Octeotride SPECT-CT test showed a mandibular tumor. Subsequently, a biopsy allowed us to identify it as a B cell Lymphoma. Unfortunately, as useful as the SPECTC with somatostatin analog Octeotride might be in identifying neuroendocrine tumors, it did not establish the presence of a phosphaturic tumor in this case [7]. Nevertheless, a later CT-scan did show a mass in the left adrenal and renal hilum - A situation not present in previous studies. The patient refused to be subject to a bone marrow aspiration and an additional biopsy. Instead, he was treated as a hight grade B Cell Lymphoma coupled with R-CHOP therapy with complete remission.

A month after completing his chemotherapy, a blood analysis showed the following levels: Creatinine $1.5 \mathrm{mg} / \mathrm{dL}$ (GFRe $66 \mathrm{ml} /$ min), Calcium $9.4 \mathrm{mg} / \mathrm{dL}$, Phosphate $2.3 \mathrm{mg} / \mathrm{dl}$, TRP 46\%, Calciuria $1.56 \mathrm{mg} / \mathrm{Kg} /$ day, Glucosuria and FGF-23: $107 \mathrm{KUA} / \mathrm{L}$ (17.6 to 28.8).

We believe that the initial hypercalcemia was induced by a "humoral factor" produced by B cell lymphoma as occurs with sarcoidosis. An increase in D Vitamin regulation could counteract the inhibition of renal hydroxylation produced by phosphatonin. Hypophosphatemia would then be induced by FGF-23 in the renal tubule. The combined effect of these factors would produce hypercalciuria and hyperphosphaturia, with a loss of bone mass. In the case in hand the bone mass decrease would take place in the trabecular bone.

The initial corticosteroid treatment stopped the hypercalcemia but did not have an effect on the patient's phosphaturia. Non the less, chemotherapy slows cellular activity indistinctly, therefore we assume that the production of FGF-23 by the splenic tumor was also affected. Unfortunately, we do not have any determinations of FGF23 during that particular period to support this hypothesis.

\section{Conclusion}

After finishing the chemotherapeutic treatment, the patient's phosphaturia increased progressively and his lumbar mass density decreased. The hypophosphatemia suggests persistent phosphaturic action of FGF-23, which resulted in hyphophosphatemic osteomalacia. At this point, the lymphoma remains in complete remission.

As accounted by related literature, the complete removal of a mesenchymal tumor causing hyphophosphatemic osteomalacia cures the syndrome. In the case in hand, after a splenectomy was performed, blood levels of phosphate and TRP went back to normal.

\section{References}

1. Jan De Beur SM (2005) Tumor-induced osteomalacia. JAMA 294: 1260-1267.

2. Komfnek P, Starek I, Gelerova M, Matousek P, ZeleniK K (2011) Phosphaturik mesenchymal tumor of the sinonasal area: Case report and 
Citation: Navas-Parejo CAM, Peña OM, Caba MM, Burbano TCM, Bravo SJ (2018) Coexisting B- Cell Lymphoma and Benign Mesenchymal Phospaturic Tumor: Debut as Acute Renal Failure Associated with Hypercalcemia and Hypophosphatemia. J Clin Case Rep 8: 1137. doi: 10.4172/2165-7920.10001137

review of the literature. Head Neck Oncol 3: 16.

3. Pfreundschuh $M$, Trümper $T$, Österborg A, Pettengell R, Trneny $M$, et al. (2006) CHOP-like chemotherapy plus rituximab versus CHOP-like chemotherapy alone in young patients with good-prognosis diff use large-Bcell lymphoma: A randomised controlled trial by the Mab Thera International Trial (MInT) Group. Lancet Oncol 7: 379-391.

4. Mariñosa M, Valderas G, Tapia G (2003) Lesiones óseas en un varón de 59 años. Medicina clínica 120: 353-356.
5. Shimada T, Mizutani S, Muto T, Yoneya T, Hino R, et al. (2001) Cloning and characterization of FGF23 as a causative factor of tumor-induced osteomalacia. Proc Nattl Acad Sci 98: 6500-6505.

6. Stewart AF (2005) Hypercalcemia associated with cancer. N Engl J Med 352 373-379.

7. Imel EA, Peacock M, Pitukcheewanont P, Heller HJ, Ward LM, et al. (2006) Sensitivity of fibroblast growth factor 23 measurements in tumor-induced osteomalacia. J Clin Endocrinol Metab 91: 2055-2061. 